\title{
Influence of the Copper-Containing SBA-15 Silica Fillers on the Mechanical Properties of High Density Polyethylene
}

\author{
Adam Gnatowski, ${ }^{1}$ Jerzy Jelonkiewicz, ${ }^{2}$ Lukasz Laskowski, ${ }^{2}$ and Magdalena Laskowska ${ }^{2}$ \\ ${ }^{1}$ Institute of Mechanical Technologies, Czestochowa University of Technology, Al. Armii Krajowej 21, 42-201 Czestochowa, Poland \\ ${ }^{2}$ Institute of Computational Intelligence, Unit of Microelectronics and Nanotechnology, Czestochowa University of Technology, \\ Al. Armii Krajowej 36, 42-201 Czestochowa, Poland
}

Correspondence should be addressed to Łukasz Laskowski; lukasz.laskowski@kik.pcz.pl

Received 5 January 2016; Revised 18 April 2016; Accepted 21 April 2016

Academic Editor: Pushpendra Kumar

\begin{abstract}
Copyright ( $) 2016$ Adam Gnatowski et al. This is an open access article distributed under the Creative Commons Attribution License, which permits unrestricted use, distribution, and reproduction in any medium, provided the original work is properly cited.

The paper concerns the mechanical properties of the high density polyethylene (HDPE) with the copper-containing SBA-15 silica filler. The considered filler is the SBA-15 mesoporous silica containing copper ions bounded inside channels via propyl-phosphonate anchoring groups. With its help, we can impart the biocidal properties to this plastic. Research covered mechanical properties, thermal analysis, colour, shine, and nanomolecular structure. Dynamical properties of the samples like modulus $E^{\prime}$ changes and mechanical core loss angle tangent $\operatorname{tg} \delta$ versus temperature and vibration frequency were tested using DMTA method. Level of crystallinity was tested using DSC method while their structure was observed with going through light by optical microscope. Hardness and toughness of obtained samples were also defined. Colour and shine changes of the samples were observed for PEHD with filler contents $0.5 \%$ and $1 \%$. Modulus value changes versus temperature and frequency were notified for the samples with modifier. There were no differences in modulus changes versus temperature for samples with and without filler and frequencies 1 and $10 \mathrm{~Hz}$. It was detected that melting enthalpy of the samples with the modifier decreases. Moreover, some influence of the samples with filler on colour and shine was observed.
\end{abstract}

\section{Introduction}

Functional materials have become very promising since 90 s of XX century, mainly due to their programmable properties. Among the functional materials significant are species based on SBA-15 mesoporous silica [1,2], which can find application as drug/gene delivery systems [3,4], biosensors [5], in separation, recycling, catalysis $[6,7]$, or electronics $[8,9]$. Silicabased nanomaterials can be used in their pure form, as coats or as plastics' modifiers. Using these materials in this last form significantly extends their application area.

The great example of functional material can be SBA-15 mesoporous silica modified by copper ions anchored inside pores via propyl-phosphonate units [10]. These species are considered in the paper. As it is commonly known, copper has strong biocidal properties [11]. Such properties are enhanced with decreasing dimensions of the copper grains. To our knowledge, nowadays, the smallest nanoparticles of copper have at least 150 of atoms [12], but those used commercially have over 100 times higher number of atoms in one grain. In our previous works $[10,13]$, we have proposed limiting dispersion of copper inside material: separate copper ions are homogenously distributed inside silica matrix.

The material containing copper ions dispersed in the silica matrix has been investigated paying special attention to its antimicrobial properties [13]. As it was shown, the material reveals comparable biocidal properties, as commercially used solution of nanocopper. Additionally, its advantage is that the copper is bounded to silica matrix, so when used for coating, the heavy metals environment contamination is limited. Another benefit of such a form is a possibility of using it as simple fillers for plastics. For this implementation, the SBA-15 mesoporous silica containing anchoring copper ions appears to be ideal. Presumably, adding this copper-containing material to selected plastics makes them biocidal. This property of the material will be tested later. Modification process of 
plastics by adding fillers seems to be relatively simple; it is sufficient to add considered filler into the plastic during melting process. Nevertheless, fillers can modify also mechanical properties of plastics, which can transfer to their commercial use constraints. In the paper, we present the influence of the copper-containing SBA-15 silica filler on the mechanical properties of the high density polyethylene (HDPE).

The features of modified material depend on structural factors of polymer as well as added modifier. The structural factors are mainly molecular weight, macromolecular chemical structure, physical layout of a chain, crystallinity, and molecular orientation while conditions of use are temperature, load time, pressure, strain type, and so on [1419]. Estimation of possible feature changes of these materials with added modifiers plays important role in polymer materials composition. Technical and economical usability of polymer materials depends on their required stiffness and strength to fulfil durability condition. Typically obtained mechanical characteristics when material is statically loaded, stretched, compressed, or twisted are not sufficient to predict its behaviour in extreme condition of usage and long exploitation time. Selection of research methods that enable prediction of material viscoelastic features change with the time, based on experimental data, is still an open problem. As tested materials are viscoelastic, all factors related to their physicomechanical features deeply depend on time and temperature. So applied research methods must consider these dependencies. One of these methods is thermal analysis of mechanical features dynamics (DMTA). It is used to measure the relaxation modules versus time with constant temperature and as a function of load change frequency and temperature [16, 19-22]. Mechanical characteristics obtained for statical load at room temperature are not adequate to estimate material's features in any other conditions of usage [16, 19-22]. The way to recognise all properties of tested materials and estimate their behaviour in predicted usage conditions is to obtain for them viscoelastic functions that contain all required thermal and time dependencies. Sinusoidal way of loading applied for tests is similar to load schemes in practice. Thermal analysis of mechanical properties dynamics (DMTA) is one of the common schemes to evaluate changes in polymer materials for wide temperature range and load frequency variation. As an effect of this analysis, we get process of dynamic Young modules changes and mechanical core loss angle tangent modification. Being familiar with these dependencies allows us to find relationship between molecular parameters and mechanical properties of polymer materials [16, 19-22]. In the paper, we presented the following properties of created materials: mechanical dynamics, thermal properties, shine, and structure.

\section{Materials and Methods}

For test, we used polyethylene Hostalen GC 7260, manufactured by Lyondell and Basell, with $0.5 \%$ and $1 \%$ filler of mesoporous SBA- 15 silica containing propyl-phosphonate units activated by copper ions in the form of powder. The filler was prepared according to the procedure described in [10]. To obtain composite, we mechanically stirred polymer

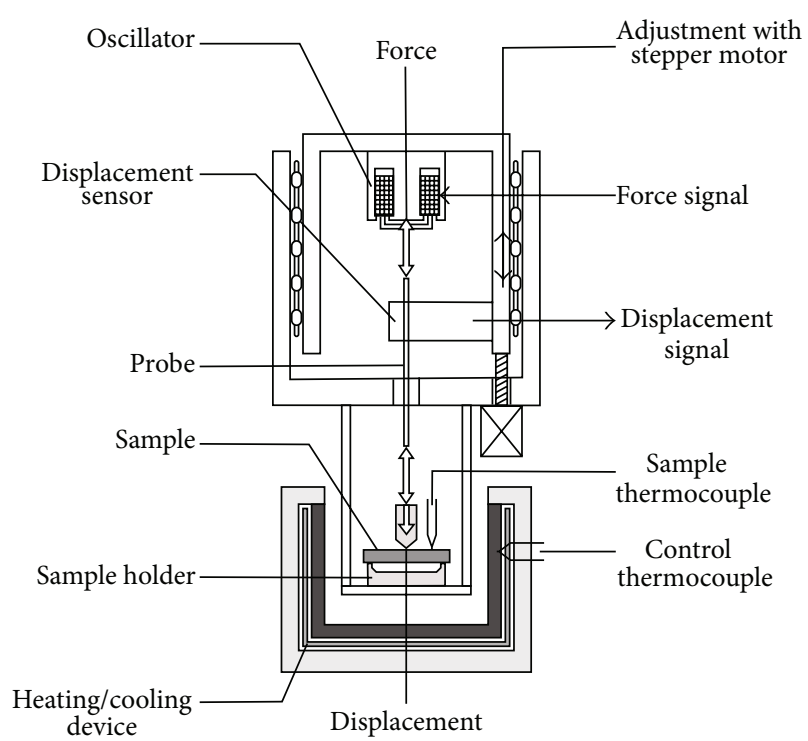

FIgURE 1: The scheme of the device for the three-point bending of sample.

with modifier and made it more flexible with a help of a screw extruder. Then, the material was granulated. We applied the following parameters of the composite extrusion:

(i) Screw rotational speed $250 \mathrm{~mm} / \mathrm{s}$.

(ii) Nozzle temperature $200^{\circ} \mathrm{C}$.

The abovementioned procedure was applied for both PE$\mathrm{HD}+0.5 \%$ weight of modifier and PE-HD $+1 \%$ weight of modifier. Samples were obtained on the extruder KRAUSS MAFFEI KM65-160C1. Applied extrusion parameters for all samples were as follows: maximal pressure in the plasticiser part $60 \mathrm{MPa}$, extrusion time $0.6 \mathrm{~s}$, clamps pressure $30 \mathrm{MPa}$, clamps time $28 \mathrm{~s}$, cooling time $15 \mathrm{~s}$, dozing time $6.6 \mathrm{~s}$, form closing force $650 \mathrm{kN}$, form temperature $-40^{\circ} \mathrm{C}$, and extrusion temperature $195^{\circ} \mathrm{C}$.

Dynamic mechanical properties were tested with a help of DMA 242 device manufactured by Netzsch with threepoint free bent grip handle of the beam sample, as it was depicted in Figure 1. Applied bent frequency was 1 and $10 \mathrm{~Hz}$ at temperature range of $-150-140^{\circ} \mathrm{C}$ with heating ramp of $2^{\circ} \mathrm{C} / \mathrm{min}$.

On the basis of the force value and the sample strain, including its size, value of modulus $E^{\prime}$, the loss module $E^{\prime \prime}$, and mechanical core loss angle tangent $\operatorname{tg} \delta$ were calculated. Obtained results were presented in the form of diagrams of the abovementioned quantities versus temperature and vibration frequency. Thermal properties of the samples were tested using DSC method while their structure was observed with going through light by optical microscope.

The DSC tests were made using scanning microcalorimeter type 200 by Netzsch. The DSC curves were taken when samples were warmed up with the ramp $10^{\circ} \mathrm{C} / \mathrm{min}$ for the temperature range of $0-160^{\circ} \mathrm{C}$. To minimize the effect surface-core, extruded samples were cut perpendicularly to the polymer material flow direction. Crystallinity level of 
the samples was determined using software available for the abovementioned device, Netzsch Proteus [23]. The program also enabled testing of the sample melting process in the abovementioned temperature range as well as marking a surface between thermographic curve and a basic line in the range of occurring endothermic peak.

The area between the DSC curve and the selected baseline is proportional to the change in enthalpy, that is, the heat consumed by the sample (endothermic) or released (exothermic). Baselines are mainly used in the calorimetry and mass spectrometry to determine peak heights and areas (enthalpy, ion currents, and total ion curve). In order to cover a multitude of possibilities, the Netzsch Proteus program offers different baseline types. For DSC measurements, it is usually necessary to correct the measuring values of the baseline. This is obvious when the tested reaction contains not only a heat of reaction, but also a change of specific heat. Baseline correction greatly influences the parameters of inverse reaction kinetics. It is also an indication that a necessary baseline correction may not be omitted. When choosing the baseline types, one must take the physicochemical facts into consideration. The straight baseline joins the start and end values of the chosen measuring range with a straight line, expressed by

$$
B(t)=D\left(t_{s}\right)+\frac{D\left(t_{f}\right)-D\left(t_{s}\right)}{\left(t_{f}-t_{s}\right)}\left(t-t_{s}\right),
$$

where $B(t)$ is a baseline value, $D(t)$ is DSC signal, $t_{s}$ is initial time, and $t_{f}$ is final time. Relation between heat flow and enthalpy can be expressed by

$$
\Delta H=\frac{F}{m \cdot K}=\frac{\int_{t_{s}}^{t_{f}}(\mathrm{HF}(t)-B(t) d t)}{m \cdot K},
$$

where $H$ is entalphy, $F$ is a peak's area, $m$ is a sample's mass, $K$ is a scale factor (sensitivity of a sensor), and HF is a heat flow.

Samples mass was between 7 and $10 \mathrm{mg}$. They were weighted using SARTORIUS weight with $0.01 \mathrm{mg}$ accuracy, internal calibration, and closed measurement chamber. Structural tests were made using optical microscope by Nikon Eclipse E200. For the tests, $10-18 \mathrm{~mm}$ thick samples were cut off from the core applied for DMTA using Thermo Electron Corporation microtome.

Colour tests were made using CIELab method applying X-rite SP60 calorimeter. The CIELab colour space is the most frequently used method to measure colour of not emitting light objects. The CIELab model is a mathematic transformation of the CIE $X Y Z$ space to allow humans to see and distinguish colours [7].

Tests results were presented in the chromatic coordinates $a, b$, and $L$. Coordinate $a$ determines colour change from green to red while $b$ determines colour change from blue to yellow, what was shown in Figure 2.

The parameter $L$ (brightness) shows colour change from black for $L=0$ to white for $L=100$. Shine test was made using Elcometer 406L Statistical Glossmeter device. Reflectometric value was taken as a shine measure of the sample

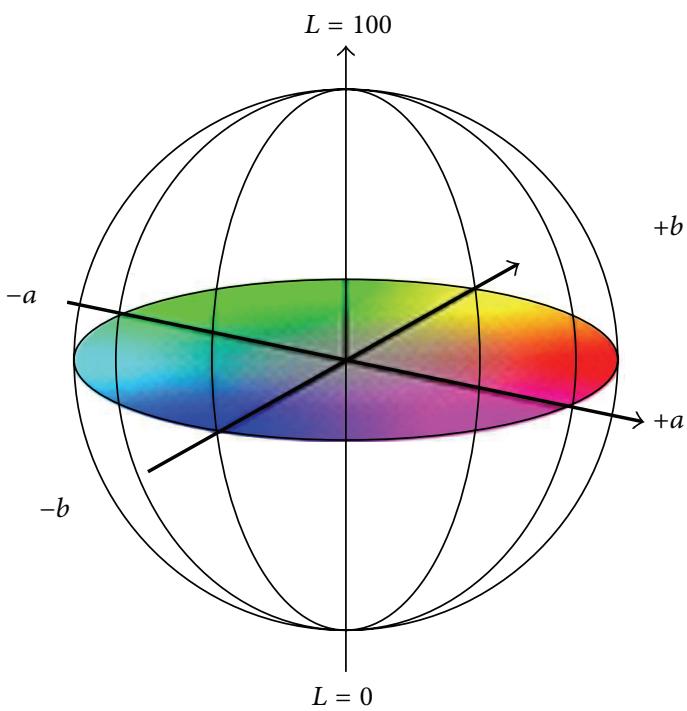

FIGURE 2: CIELab space.

surface which is a relation of light stream reflected from the surface to the light stream that falls to this surface. This test measured intensity of reflected and dissipated light for narrow reflection angle $\left(20^{\circ}\right)$. Reflected light intensity depends on the light refraction, absorption, transparency, and kind of surface. The shine measurements results were represented in shine units GU (gloss units).

\section{Results and Discussion}

Figures 3(a)-3(c) show thermomechanical curves of polyethylene and modified materials that were obtained from DMTA tests. Modulus values and mechanical core loss coefficient are different for investigated materials. Provided tests show that modifier diminishes modulus value (Figures 3(b) and 3(c)). In the glassy range material is hard and brittle which means that thermal energy is insufficient to break the barrier for shifting and rotational movement of particles segments. The material is in the thermodynamical unbalance. The modulus values decrease for both polyethylene (Figure 3(a)) and modified polyethylene (Figures 3(b) and 3(c)) with rising temperature. In the glassy transformation range, some Brown movement in the molecular chain is initiated. Thermal energy is becoming comparable with potential energy barrier for molecular rotation. In the neighborhood of the glassy transformation temperature, the viscoelastic properties of tested materials are changing fast with the time and temperature. In this range, lower values were observed for lower contents of the modifier (Figure 3(b)). The modulus value increases with the higher modifier contents (Figure $3(\mathrm{c})$ ). In the highly elastic entropic strains, temperature influence on module $E^{\prime}$ is the same for both tested materials. In the last range, the module value is very low and the material is in the liquid state so it is unable to come back to its previous shape. For both materials, the same tendency of the module value decrease is observed. The mechanical core loss angle $\operatorname{tangent} \operatorname{tg} \delta$ curve looks the same for both materials and 


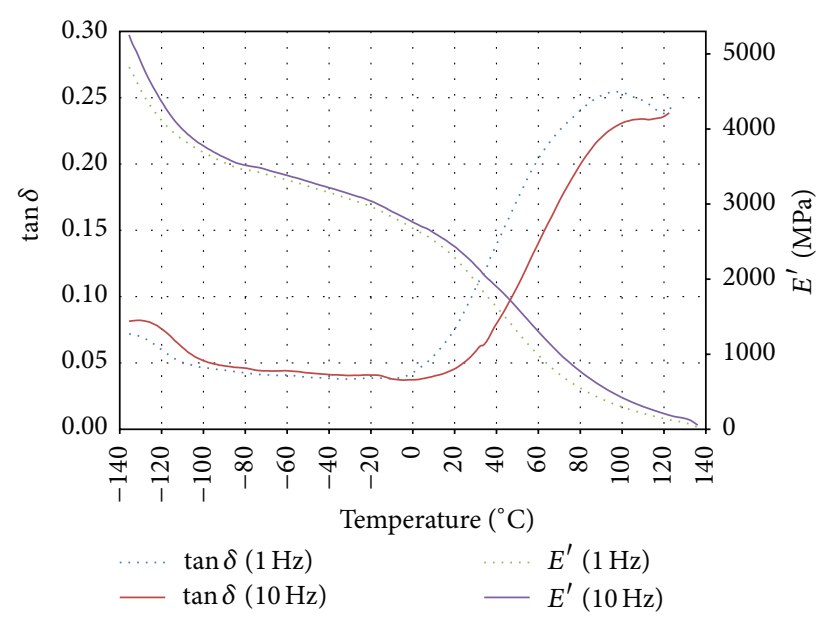

(a)

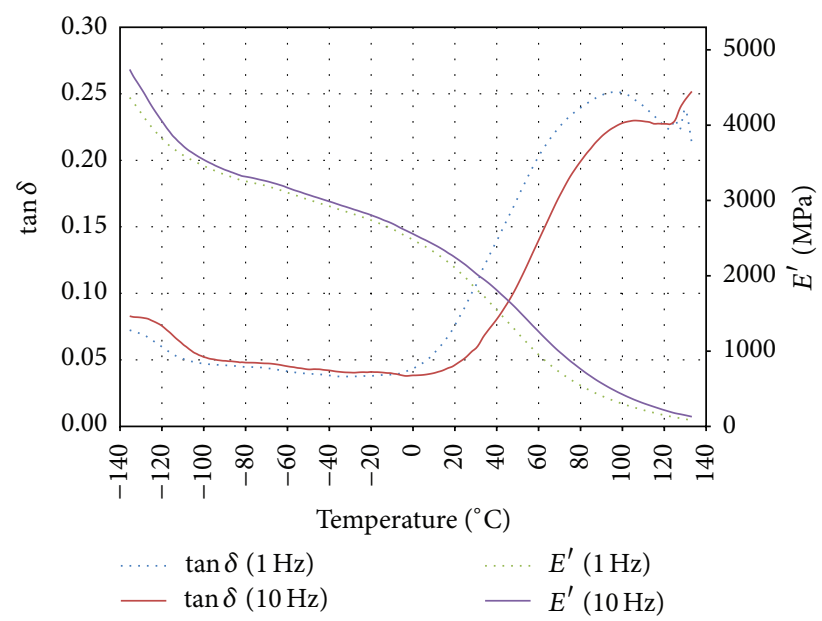

(b)

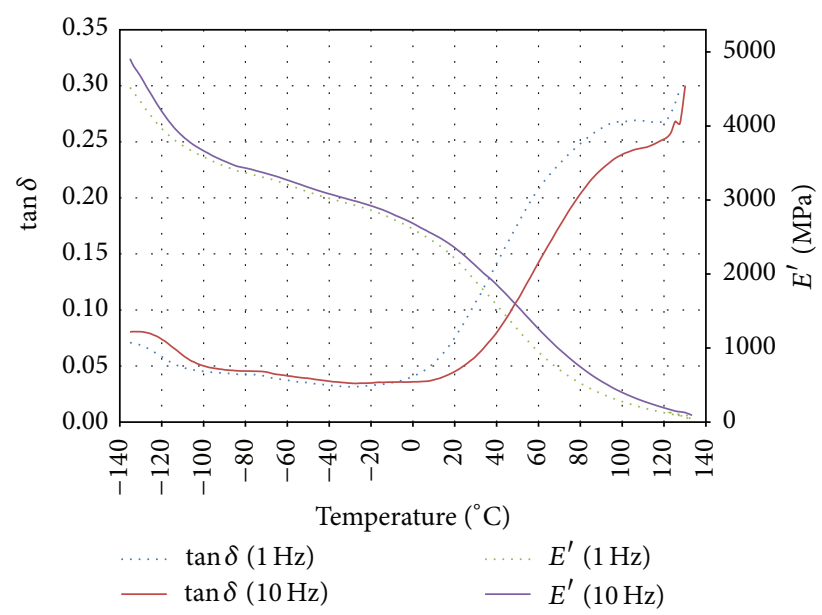

(c)

FIgURE 3: The dependence of the storage modulus value and mechanical loss tangent versus temperature of tested materials: (a) PE-HD, (b) PE-HD/0.5\% modifier, and (c) PE-HD/1\% modifier. considered vibration frequencies. The only difference relates to the slight movement of its value corresponding to the maximum temperature for the material with higher contents of the modifier (Figure 3(c)). Considering the mechanical core loss angle tangent $\operatorname{tg} \delta$ curve, we can notice that material with $1 \%$ contents of the modifier shows better damping properties when compared with the material with its lower contents or not modified.

Figure 4 presents the DSC thermograms for tested materials.

For sample with added modifier amount of absorbed energy was diminishing. Also, melting enthalpy for modified materials was changing.

The crystallinity degree of the material was decreasing with the higher contents of the modifier. The maximal melting and crystallizing temperature was the same for both materials while the melting temperature range as well as the crystallizing temperature range was narrowing.

Likely, the crystallite level change for modified polyethylene was caused by diminishing number of heterogenous nucleation centres. With higher amount of modifier and less nucleation process, the crystal phase growth of the polymer base was reduced. Some modifiers added to semicrystal polymer increase base crystalizing temperature and affect diminishing crystallites size while changing participation of the crystal phase $[24,25]$.

Investigated structure of both materials showed fragmentation of the crystalline structure (Figure 5). When polyethylene is compared with other semicrystalline plastics, it reveals quite well developed structure with visible shape, big spherulite (Figure 5(a)). Optical microscope observation of the modified materials shows fragmentation of the crystal structure, particularly for higher contents of the modifier (Figure 5(c)).

For both pure (Figure 5(a)) and modified (Figures 5(b) and 5(c)) polyethylene, the structure is well seen and ordered.

Figures 6,7 , and 8 show $L, a$, and $b$ values of tested polymer materials.

The modifier changes the luminance value $L$. It is connected with the modifier colour and its contents in the polymer as well as its discretion and reactivity to polymer. For the polyethylene with the modifier, the $L$ value is decreased (Figure 6) which indicates that the moulders are darker.

Increasing amount of the modifier in the polymer effects some small decrease of its luminance. So samples with $1 \%$ contents of the modifier are a little darker than those with $0.5 \%$ contents which indicates smaller influence of the modifier on polymer luminance.

Changes of $a$ and $b$ coordinates for tested materials prove significant influence of the modifier on colour (Figures 7 and 8). More modifier contents resulted in higher saturation of green colour in the samples.

Results of the shine change of tested materials are presented in Figure 9.

The lowest shine values were observed for the higher contents of the modifier in the material. 


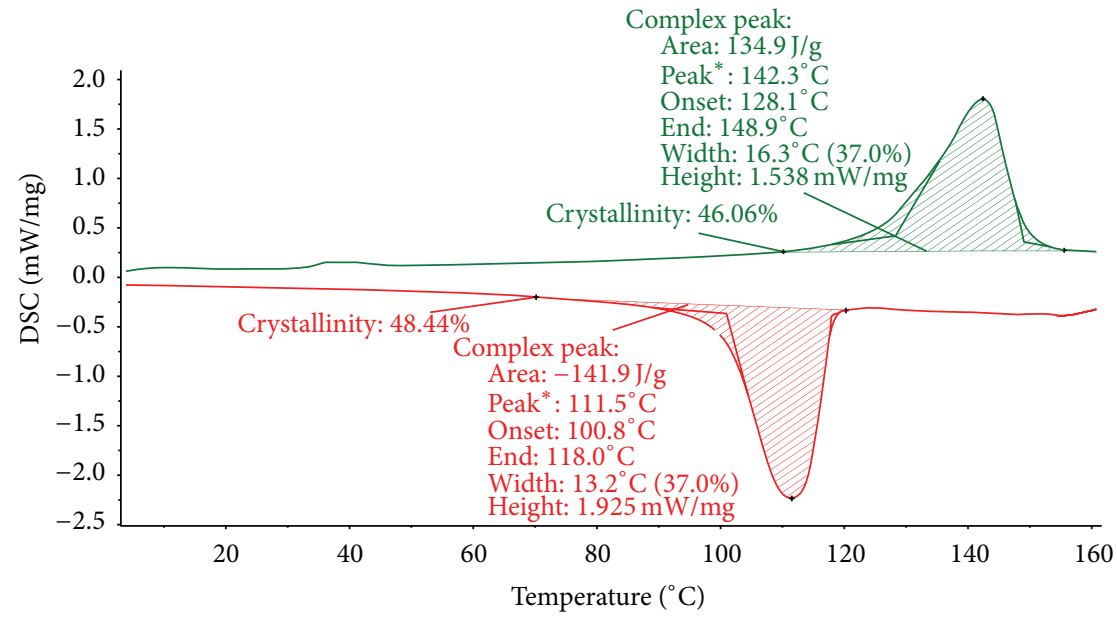

(a)

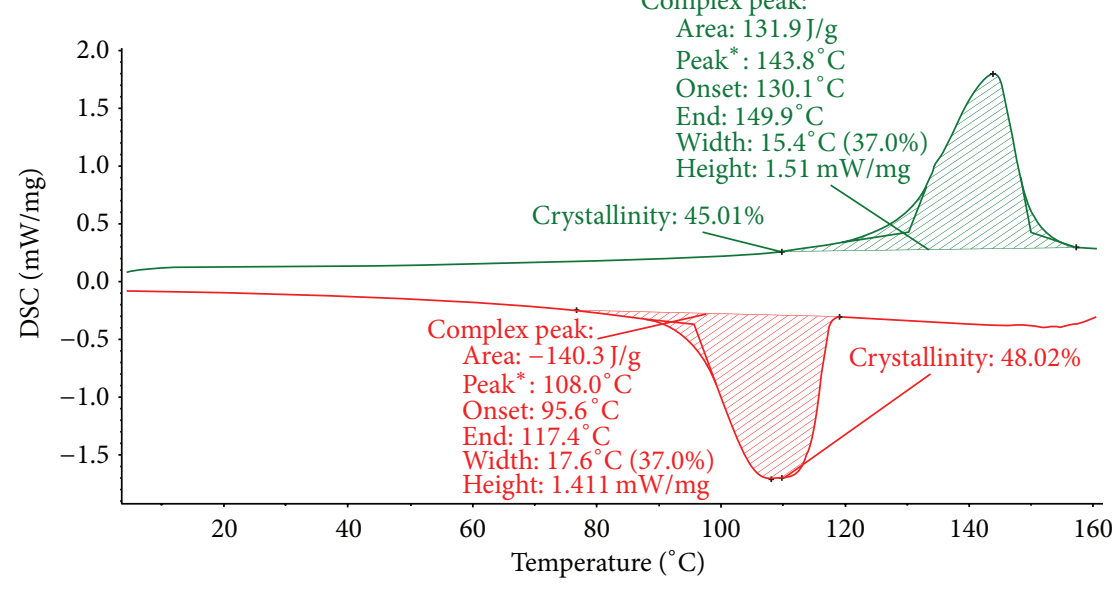

(b)

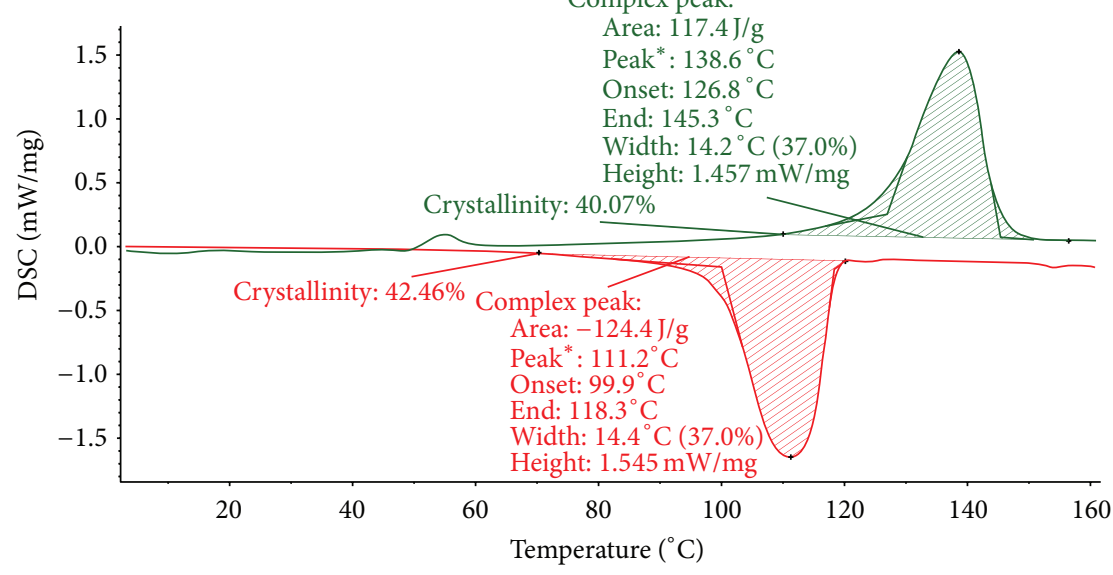

(c)

FIgure 4: DSC thermograms of (a) PE-HD, (b) PE-HD/0.5\% modifier, and (c) PE-HD/1\% modifier. Peak ${ }^{*}$ means the position of the peak maximum. 


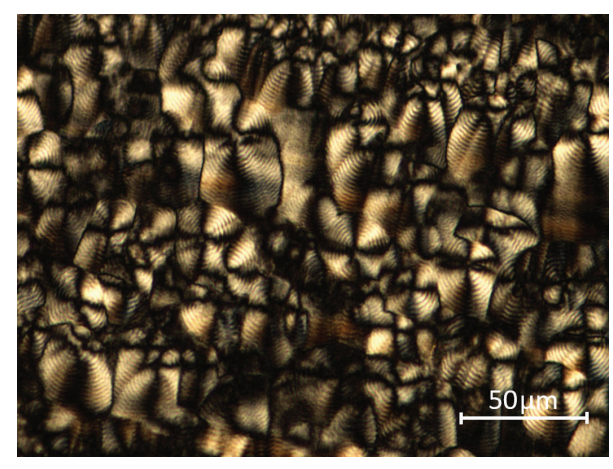

(a)

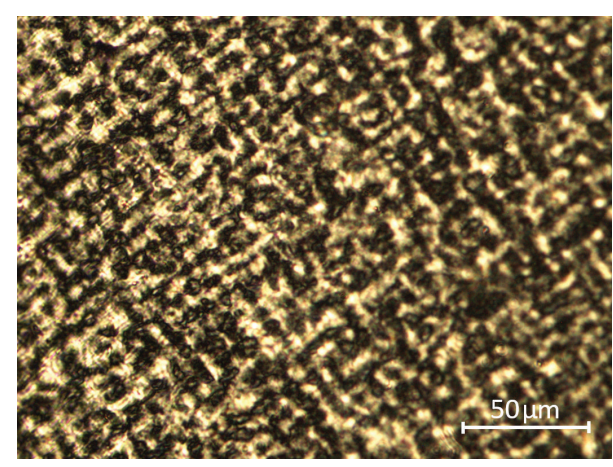

(b)

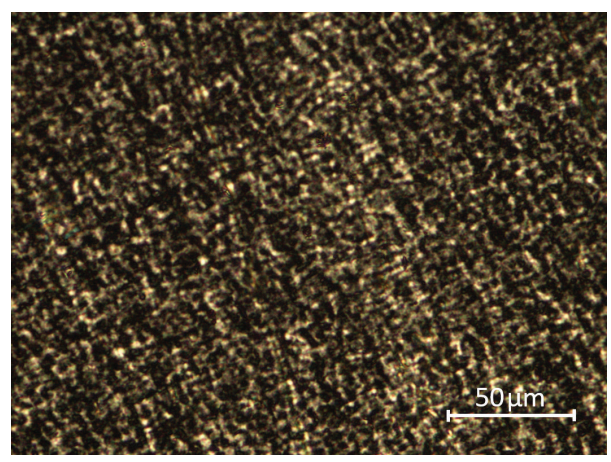

(c)

FIGURE 5: Structures observed on optical microscope with the magnification 350x: (a) PE-HD, (b) PE-HD/0.5\% modifier, and (c) PE-HD/1\% modifier.

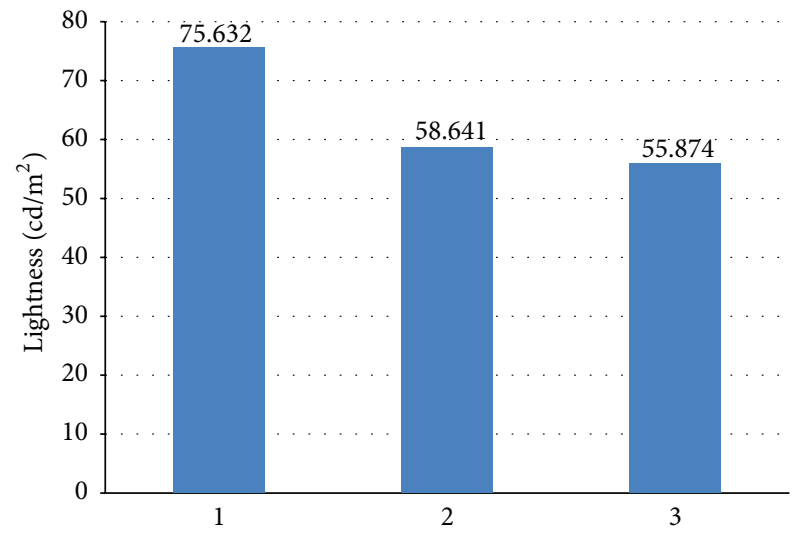

FIGURE 6: The lightness $L$ of the examined polymer materials: 1 : PE$\mathrm{HD}, 2$ : PE-HD/0.5\% modifier, and 3: PE-HD/1\% modifier.

\section{Conclusion}

We observed influence of active SBA-15 silica filler on mechanical properties of high density polyethylene. Adding $0.5 \%$ and $1 \%$ of copper-containing modifier significantly diminished $E^{\prime}$ modulus value. This divergence varies depending on temperature. In the same time, the loss angle tangent seems to have similar graph for pure HDPE and modified material. The only difference is in slight shift of maximum

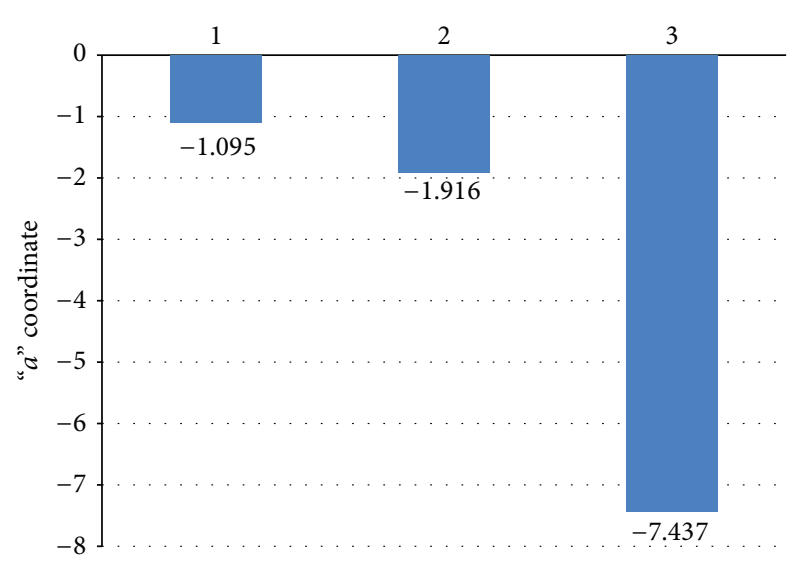

FIGURE 7: The value of $a$ coordinate for the examined polymer materials: 1: PE-HD, 2: PE-HD/0.5\% modifier, and 3: PE-HD/1\% modifier.

losses in the case of modified sample. Material containing $1 \%$ of modifier has better dumping properties than pure HDPE.

DSC research showed that adding of silica modifier significantly decreases crystallinity of the polyethylene, while maximum temperature of melting and crystallization stays unchanged. Nevertheless, after adding filler, the range of melting and crystallization temperature was narrowed.

The colour of the modified samples changed significantly. After adding copper-containing silica modifier, samples 


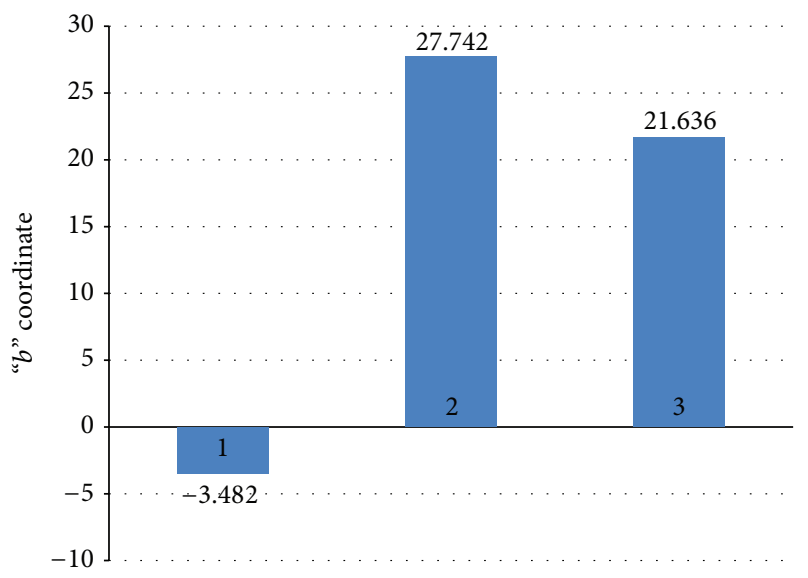

Figure 8: The value of $b$ coordinate for the examined polymer materials: 1: PE-HD, 2: PE-HD/0.5\% modifier, and 3: PE-HD/1\% modifier.

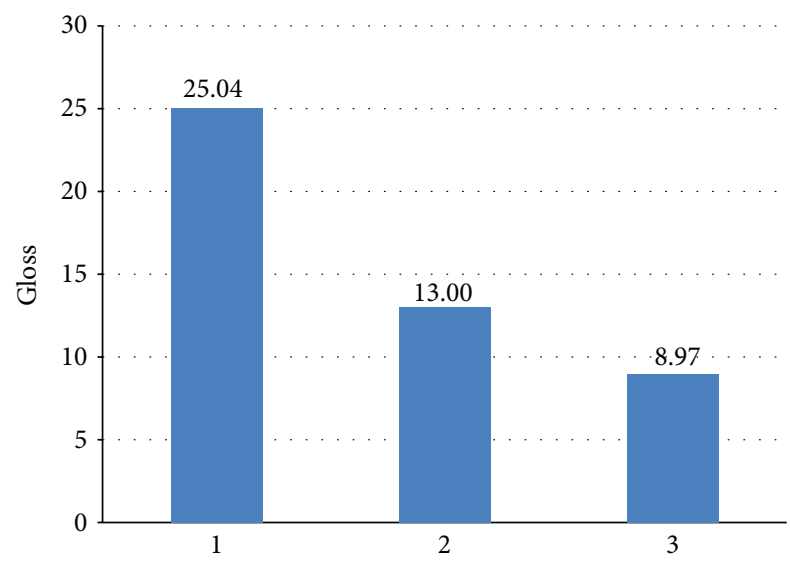

FIGURE 9: Gloss of the examined polymer materials: 1: PE-HD, 2: $\mathrm{PE}-\mathrm{HD} / 0.5 \%$ modifier, and 3: PE-HD/1\% modifier.

become green with colour saturation depending on the filler contents. Also, the gloss of the material changed as a result of modification. With increasing modifier contents, we observed decreasing HDPE gloss.

\section{Competing Interests}

The authors declare that they have no competing interests.

\section{Acknowledgments}

Financial support for this investigation has been provided by the National Centre of Science (Grant no. 2011/03/D/ST5/ 05996).

\section{References}

[1] J. S. Beck, J. C. Vartuli, G. J. Kennedy, C. T. Kresge, W. J. Roth, and S. E. Schramm, "Molecular or supramolecular templating: defining the role of surfactant chemistry in the formation of microporous and mesoporous molecular sieves," Chemistry of Materials, vol. 6, no. 10, pp. 1816-1821, 1994.
[2] J. S. Beck, J. C. Vartuli, W. J. Roth et al., "A new family of mesoporous molecular sieves prepared with liquid crystal templates," Journal of the American Chemical Society, vol. 114, no. 27, pp. 10834-10843, 1992.

[3] L. Giraldo and J. C. Moreno-Piraján, "Calorimetric study of mesoporous SBA-15 modified for controlled valproic acid delivery," Journal of Chemistry, vol. 2013, Article ID 267464, 11 pages, 2013.

[4] D. Halamová, M. Badaničová, V. Zeleňák, T. Gondová, and U. Vainio, "Naproxen drug delivery using periodic mesoporous silica SBA-15, Applied Surface Science, vol. 256, no. 22, pp. 6489-6494, 2010.

[5] J. Zhang and J. Zhu, "A novel amperometric biosensor based on gold nanoparticles-mesoporous silica composite for biosensing glucose," Science in China Series B: Chemistry, vol. 52, no. 6, pp. 815-820, 2009.

[6] Y. Park, T. Kang, J. Lee, P. Kim, H. Kim, and J. Yi, "Single-step preparation of $\mathrm{Ni}$ catalysts supported on mesoporous silicas (SBA-15 and SBA-16) and the effect of pore structure on the selective hydrodechlorination of 1,1,2-trichloroethane to VCM," Catalysis Today, vol. 97, no. 2-3, pp. 195-203, 2004.

[7] F.-S. Xiao, "Ordered mesoporous materials with improved stability and catalytic activity," Topics in Catalysis, vol. 35, no. 1-2, pp. 9-24, 2005.

[8] G. Wirnsberger, P. Yang, B. J. Scott, B. F. Chmelka, and G. D. Stucky, "Mesostructured materials for optical applications: from low-k dielectrics to sensors and lasers," Spectrochimica Acta Part A: Molecular and Biomolecular Spectroscopy, vol. 57, no. 10, pp. 2049-2060, 2001.

[9] X. Wang and H. Yang, "A dansyl group modified SBA-15 INHIBIT logic gate with $\left[\mathrm{Hg}^{2+}\right.$ and $\left.\mathrm{Cl}^{-}\right]$or $\left[\mathrm{Hg}^{2+}\right.$ and $\left.\mathrm{Br}^{-}\right]$as inputs," Applied Surface Science, vol. 277, pp. 257-262, 2013.

[10] L. Laskowski and M. Laskowska, "Functionalization of SBA-15 mesoporous silica by $\mathrm{Cu}$-phosphonate units: probing of synthesis route," Journal of Solid State Chemistry, vol. 220, pp. 221-226, 2014.

[11] J. P. Ruparelia, A. K. Chatterjee, S. P. Duttagupta, and S. Mukherji, "Strain specificity in antimicrobial activity of silver and copper nanoparticles," Acta Biomaterialia, vol. 4, no. 3, pp. 707-716, 2008.

[12] L. Argueta-Figueroa, R. A. Morales-Luckie, R. J. ScougallVilchis, and O. F. Olea-Mejía, "Synthesis, characterization and antibacterial activity of copper, nickel and bimetallic $\mathrm{Cu}-\mathrm{Ni}$ nanoparticles for potential use in dental materials," Progress in Natural Science: Materials International, vol. 24, no. 4, pp. 321328,2014

[13] M. Laskowska, L. Laskowski, K. Fijałkowski, and M. Kacprzak, "Synteza i właściwości fizykochemiczne krzemionki typu SBA15 aktywowanej jonami miedzi," Inżynieria Materiałowa, vol. 35, no. 6, pp. 516-518, 2014.

[14] H. Blom, R. Yeh, R. Wojnarowski, and M. Ling, "Detection of degradation of ABS materials via DSC," Thermochimica Acta, vol. 442, no. 1-2, pp. 64-66, A collection of papers from the 32nd Conference of North American Thermal Analysis Society, 2006.

[15] A. Gnatowski and J. Koszkul, "Investigations of the influence of compatibilizer and filler type on the properties of chosen polymer blends," Journal of Materials Processing Technology, vol. 162-163, pp. 52-58, 2005.

[16] A. Gnatowski and J. Koszkul, "Investigation on PA/PP mixture properties by means of DMTA method," Journal of Materials Processing Technology, vol. 175, no. 1-3, pp. 212-217, 2006. 
[17] K. P. Pramoda and T. Liu, "Effect of moisture on the dynamic mechanical relaxation of polyamide-6/clay nanocomposites," Journal of Polymer Science Part B: Polymer Physics, vol. 42, no. 10, pp. 1823-1830, 2004.

[18] M. Maity, B. B. Khatua, and C. K. Das, "Effect of processing on the thermal stability of the blends based on polyurethane: part IV," Polymer Degradation and Stability, vol. 72, no. 3, pp. 499503, 2001.

[19] A. Gnatowski, "Influence of the polyvinylpyrrolidone modification on crystallines and properties of selected thermoplastic polymers," Journal of Polymer Engineering, vol. 27, no. 6-7, pp. 507-524, 2007.

[20] T. D. Papathanasiou and M. R. Kamal, "Filling of a complexshaped mold with a viscoelastic polymer. Part I: the mathematical model," Polymer Engineering \& Science, vol. 33, no. 7, pp. 400-409, 1993.

[21] M. S. Perera, U. Ishiaku, and Z. M. Ishak, "Characterisation of PVC/NBR and PVC/ENR50 binary blends and PVC/ENR50/ NBR ternary blends by DMA and solid state NMR," European Polymer Journal, vol. 37, no. 1, pp. 167-178, 2001.

[22] R. E. Wetton, "Dynamic mechanical method in the characterisation of solid polymers," Polymer Testing, vol. 4, no. 2-4, pp. 117-129, 1984.

[23] https://www.netzsch-thermal-analysis.com/us/productssolutions/software/proteus/.

[24] B. Wunderlich, "Reversible crystallization and the rigid-amorphous phase in semicrystalline macromolecules," Progress in Polymer Science, vol. 28, no. 3, pp. 383-450, 2003.

[25] S. S. Ray and M. Okamoto, "Polymer/layered silicate nanocomposites: a review from preparation to processing," Progress in Polymer Science, vol. 28, no. 11, pp. 1539-1641, 2003. 

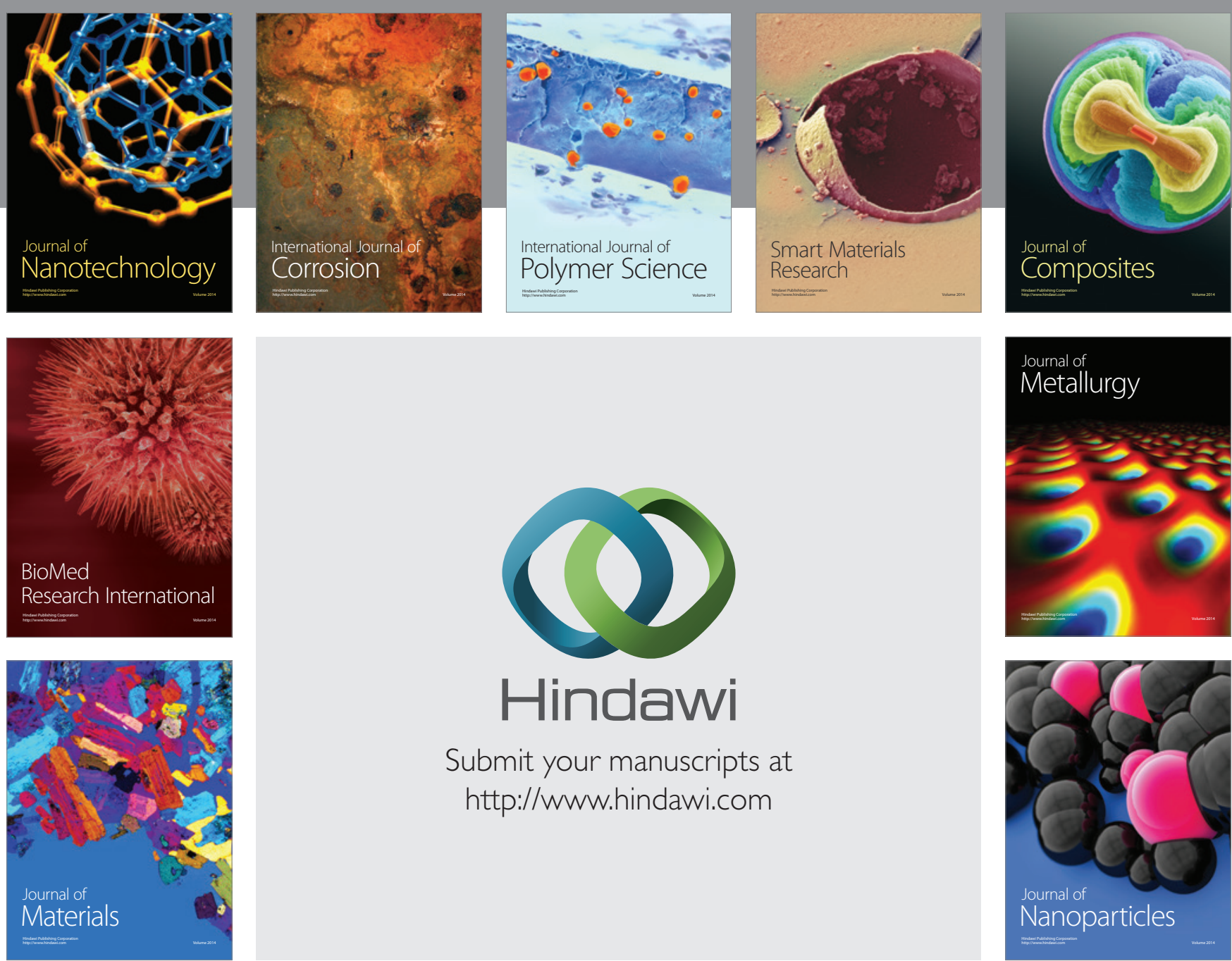

\section{Hindawi}

Submit your manuscripts at

http://www.hindawi.com

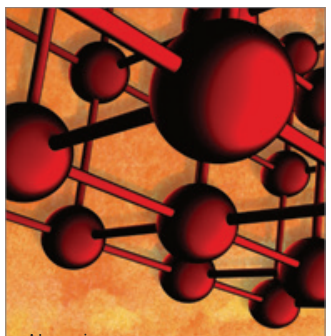

Materials Science and Engineering
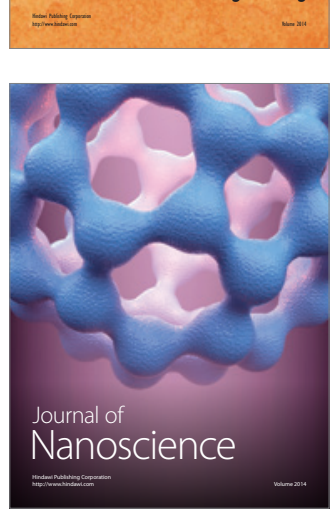
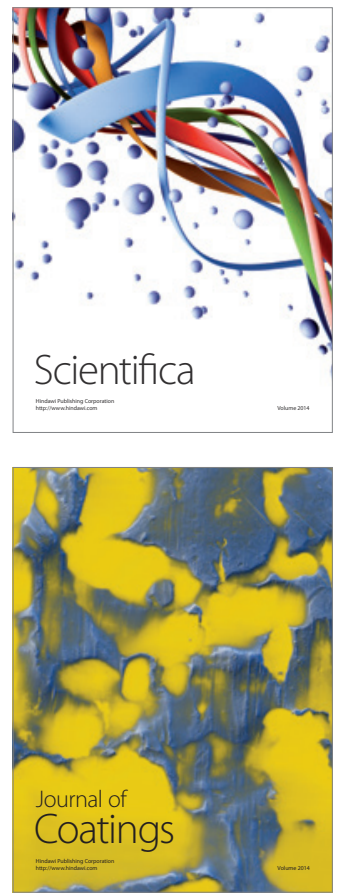
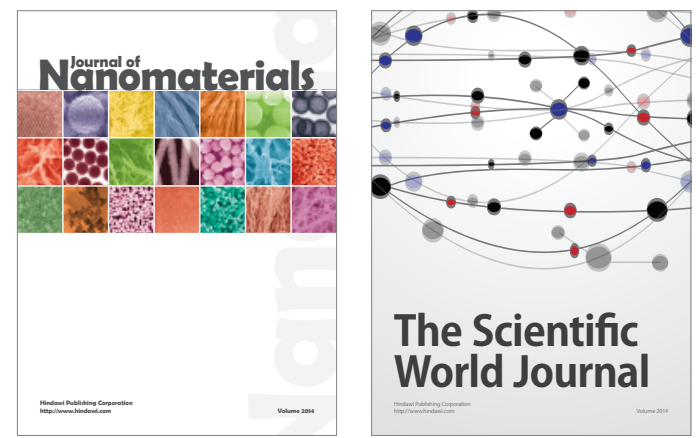

The Scientific World Journal
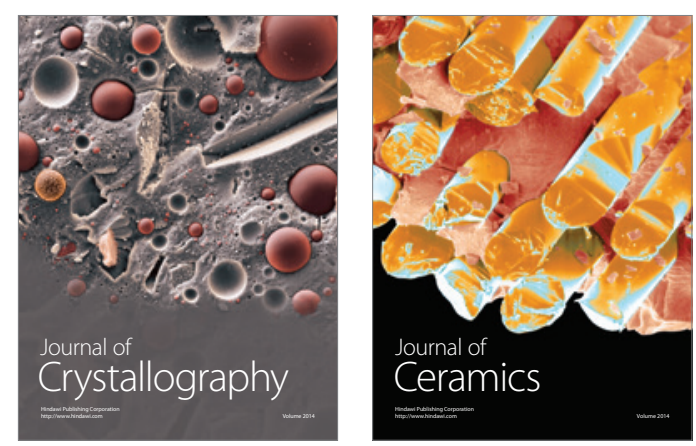
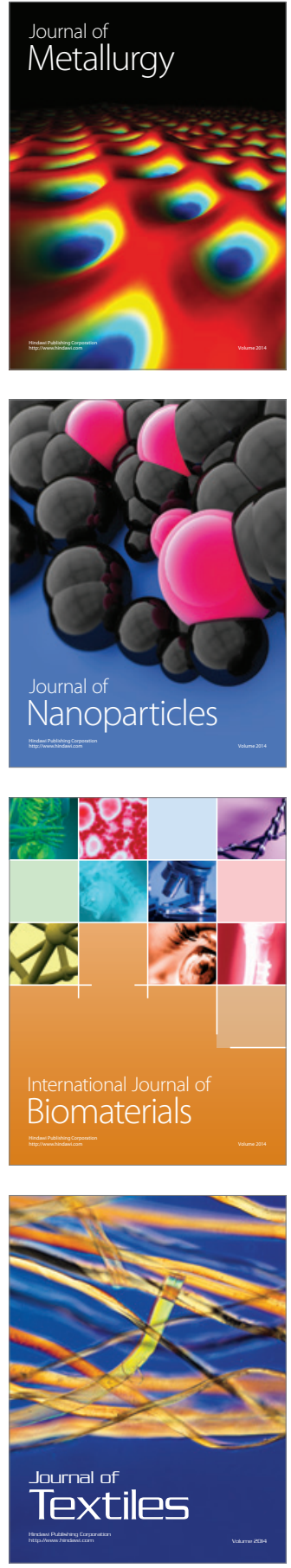